Sains Malaysiana 47(9)(2018): 2195-2204

http://dx.doi.org/10.17576/jsm-2018-4709-30

\title{
Variance Targeting Estimator for GJR-GARCH under Model's Misspecification
}

(Penganggar Sasaran Varians untuk GJR-GARCH di bawah Model Spesifikasi Ralat)

\author{
MuHAMmAd ASMU'I ABDUl RAHIM, Siti MERIAM ZAHARI \& S. SARIFAH RADIAH SHARIFF
}

\begin{abstract}
The application of the Variance Targeting Estimator (VTE) is considered in GJR-GARCH(1,1) model, under three misspecification scenarios, which are, model misspecification, initial parameters misspecification and innovation distribution assumption misspecification. A simulation study has been performed to evaluate the performance of VTE compared to commonly used, which is the Quasi Maximum Likelihood Estimator (QMLE). The data has been simulated under GJR-GARCH(1,1) process with initial parameters $\omega=0.1, \alpha=0.05, \beta=0.85, \gamma=0.1$ and an innovation with a true normal distribution. Three misspecification innovation assumptions, which are normal distribution, Student-t distribution and the GED distribution have been used. Meanwhile, for the misspecified initial parameters, the first initial parameters have been setup as $\omega=1, \alpha=0, \beta=0$ and $\gamma=0$. Furthermore, the application of VTE as an estimator has also been evaluated under real data sets and three selected indices, which are the FTSE Bursa Malaysia Kuala Lumpur Index (FBMKLCI), the Singapore Straits Time Index (STI) and the Jakarta Composite Index (JCI). Based on the results, VTE has performed very well compared to QMLE under both simulation and the applications of real data sets, which can be considered as an alternative estimator when performing GARCH model, especially the GJR-GARCH.
\end{abstract}

Keywords: GJR-GARCH; QMLE; variance targeting; volatility

ABSTRAK

Penggunaan Penganggar Sasaran Varians (VTE) telah dipertimbangkan terhadap model GJR-GARCH $(1,1)$ menggunakan tiga senario spesifikasi ralat, iaitu terhadap model, parameter awalan dan andaian taburan hingar. Kajian simulasi telah dilakukan untuk menilai prestasi VTE berbanding dengan Penganggar Kebolehjadian Kuasa Maksimum (QMLE). Data telah disimulasikan di bawah proses $\operatorname{GJR-GARCH}(1,1)$ dengan parameter awalan, $\omega=0.1, \alpha=0.05, \beta=0.85, \gamma$ $=0.1$ dan hingar yang dianggap mempunyai taburan sebenar yang normal. Tiga andaian telah digunakan terhadap spesifikasi ralat bagi taburan hingar iaitu taburan normal, taburan t dan taburan GED. Sementara itu, spesifikasi ralat bagi parameter awalan telah ditetapkan sebagai $\omega=1, \alpha=0, \beta=0$ dan $\gamma=0$. Selain itu, penggunaan VTE sebagai penganggar juga telah dinilai menggunakan data sebenar iaitu Indeks FTSE Bursa Malaysia Kuala Lumpur (FBMKLCI), Indeks Masa Selat Singapura (STI) dan Indeks Komposit Jakarta (JCI). Berdasarkan keputusan analisis, VTE menunjukkan hasil anggaran yang lebih baik berbanding QMLE bagi kedua-dua kajian simulasi dan kajian berasaskan data sebenar. Oleh itu, VTE boleh digunakan sebagai penganggar alternatif bagi model GARCH, terutamanya GJR-GARCH.

Kata kunci: GJR-GARCH; QMLE; penganggar sasaran varians (VTE); volatiliti

\section{INTRODUCTION}

The Stock Market Index is one of the key indicators that mirror the underlying country's economy. It consists of the top performing companies that have been selected by stock market regulators. These companies are the representative of their sector, thus they become the performance indicators of the country's economy. In Malaysia, the FTSE Bursa Malaysia Kuala Lumpur Index (FBMKLCI) has been used as the main market indices. It contains the top 30 companies based on market capitalisation and this index is constantly regulated by FTSE and Bursa Malaysia.

At the moment, the global markets have closely emerged if compared to the past years, as a result of the increase in financial integrations. This is because, as a part of the Association of Southeast Asian Nations
(ASEAN), Malaysia has participated in many joint economic activities and treaties such as the ASEAN Economic Community Blueprint that could help boost the mutual and simultaneous growth among individual members' countries as well as the collective progress of the region's economy. On the other hand, the prevalence of such community comes with a drawback. The financial markets are now more exposed to the global economy and this will lead to a more volatile market when compared to the past decade. Recent events such as the Greek debt problem, the devaluation of the Yuan currency, and the upcoming new interest rate announcement by the Federal Reserve would without a doubt affect the regional economy. This generates many interests as shown in the studies by Narayan and Smyth (2005) and Tsukuda et al. (2017), which focused 
on the integration of markets between different countries. Meanwhile, Lim and Sek (2013), Oh et al. (2010) and Shamiri and Isa (2009) are among the local studies that have analysed the volatility of the Malaysian stock market. On the other hand, understanding the dynamics of market volatility is not an easy task; nonetheless, it plays an important role in measuring risk exposures. This is because a better forecast of the volatility of stock returns will lead to a more accurate portfolio selection that eventually reduces the future risks that will be faced by the investors. One volatility model that has received wide attention in financial literature is the Generalised Autoregressive Conditional Heteroscedasticity (GARCH) model by Bollerslev (1986), which is an extension of the ARCH model introduced by Engle (1982).

Furthermore, studies about the relationships between news and volatility are a part of the important key characteristics in evaluating how volatile the markets can react in the presence of news. A previous research by Engle and $\mathrm{Ng}$ (1993) has extended the study on the effects of news on volatility, based on the empirical evidences by Black (1976). They have proposed the use of the sign bias test in the process of diagnosing and examining the existence of a leverage effect. Moreover, the advances in information and communication technology have enabled news to spread faster than ever before. This factor has motivated Foucalt et al. (2016) to study the investors' reactions towards news. The study has classified the investors into two groups; first, a group with precise news and second, a group that depends on news or rumours that spread faster. In all, Foucalt et al. (2016) concluded that the group that depends on news speed tends to have higher volatility than the group with the precise information. Meanwhile, Islam and Sultana (2015) studied the existence of the 'day of the week' effects in stock returns and market volatility. The study showed that the 'day of the week' effects are present due to the fact that important news are predominantly announced during the weekend and this may affect the investors' behaviour to sell their holdings on the first day of market opening (Mehdian \& Perry 2001).

Concurrently, the standard GARCH models have failed to capture this characteristic. Hence, this causes the researchers to propose the use of an asymmetry GARCH in forecasting volatility by considering the impact of news. An example of such models are EGARCH model by Nelson (1991) and the GJR-GARCH model by Glosten et al. (1993). This model allows positive and negative returns to have different impacts on conditional variance. Among other works that have used GJR-GARCH are Casarin et al. (2013), Cappiello et al. (2006) and Maheu and McCurdy (2004). An empirical analysis by Almeida and Hotta (2014) compares several asymmetry models for GARCH models including TGARCH, EGARCH and GJR-GARCH and compare its performance in estimating Brazilian Stock Market volatility. It was found that the GJR-GARCH was the most selected model by all the selection criteria compared to other models. On the other hand, based on empirical finding by Thalassinos et al. (2014), it was found that EGARCH is the best model is forecasting the volatility in the Czech Republic Stock Market. Dutta (2014) applied the EGARCH and GJR-GARCH model and based on the empirical results, it was found that the good news has impact on volatility more that bad news under different distribution assumption.

Besides that, the parameter estimation process is very important and careful consideration needs to be taken to ensure the model's performance. However, a commonly used quasi-maximum likelihood estimator (QMLE) may not be considered as appropriate to be used in the state of turbulent market (Iqbal 2013). Thus, practitioners are often reluctant to apply QMLE directly to their model estimation process. This opens the possibility to consider an alternative estimator besides QMLE in such environment. Based on a recent literature, researchers have focused on using alternative estimators for QMLE. Researches by Boudt and Croux (2010) and Mukherjee (2008) mentioned that many studies have advised that the use of the Gaussian likelihood estimator is often not suitable. This is due to the large numbers of outliers in the estimator's variable. Thus, Muler and Yohai (2008) proposed a modification towards the M-estimates and called it the 'bounded M-estimation'. Meanwhile, Boudt and Croux (2010) proposed to use the M-estimator with loss functions on BEKK GARCH and later extended its usage on DCC GARCH. Furthermore, Boudt et al. (2013) and Iqbal (2013) proposed robust estimations of multivariate GARCH models and collected empirical evidences of the best predictive potential estimators, such as the least absolute deviation (LAD) by Peng and Yao (2003) and B-estimator. These researches concluded that the use of LAD and B-estimator have provided better estimations than QMLE.

Consequently, among the alternative estimators, the most appealing estimator to study is the variance targeting estimator (VTE) as proposed by Engle and Mezrich (1996). VTE has been proven to be robust to the model misspecification by Francq et al. (2009); the study has discovered the advantages and disadvantages of VTE while mentioning the asymptotic properties for $\operatorname{GARCH}(1,1)$. It has been discovered that even though it is robust to initial misspecifications, the existence of the finite fourth order moments is a must in order to ensure that it sustains the asymptotic normality of the VTE. However, this study is limited to the application of $\operatorname{GARCH}(1,1)$. Meanwhile, Vaynman and Beare (2013) proposed the stable limit theory for VTE and also stated the asymptotic properties of VTE for GARCH (p,q), whereas Francq et al. (2016) extended the application to a multivariate GARCH. In addition, Francq et al. (2016) also showed a moments targeting for the asymmetric CCC-GARCH based on GJR-GARCH $(1,1)$ model. Thus, it is the reason why we interested to extend the study on GJR-GARCH compares to EGARCH model as the moment targeting for GJR-GARCH is already established. Pedersen and Rahbek (2014) had also focused on the use of VTE in multivariate GARCH and established a theory on large sample properties of VTE called the BEKK-GARCH model. The study used variance targeting, which has been known to reduce the estimation processing times and as 
a result, lowers the burden of any computerizing needs. Overall, all the researchers agreed on the simplicity of VTE. Additionally, Pedersen and Rahbek (2014) confirmed that VTE is more efficient as compared to QMLE when both known estimators are considered to be asymptotically normal. However, the need of the fourth order moments in performing VTE is crucial to ensure its performance. The findings is also supported by Abdul Rahim et al. (2017) who compared the performance of VTE and QMLE in $\operatorname{GARCH}(1,1)$ under misspecified error distribution. It is found out that the VTE outperforms QMLE, especially when the error distribution is not the same as true underlying error distribution.

On the other hand, model misspecification can occur when researchers cannot truly determine the true characteristics of the financial data. For instance, Yaya et al. (2014) estimated and forecasted the GARCH model under the misspecified probability distribution and tested the model using three distributions, which are normal, Student's t and Generalised Error Distribution (GED). The study concluded that GED performed better under a misspecified error distribution. In the meantime, Francq et al. (2009) tested VTE on two case designs to test how misspecified initial parameters can affect the parameters for the performances of the estimation model and found that VTE has performed better. Early studies such as by Nelson and Foster (1995) have also examined how misspecified models can affect the models' performances.

The main purpose of this study was to investigate how GJR-GARCH will be affected when there are misspecification in modeling process. Hence, a simulation study is set to show that the misspecification can be handle well by VTE compares to QMLE, especially in modeling the GJR-GARCH. This process will ensure the misspecification problem in modeling the real datasets is well captured by the chosen estimator. Meanwhile, the empirical results that will be used and discussed are the FBMKLCI index data, Singapore Straits Times Index (STI), and Jakarta Composite Index (JCI).

\section{MATERIALS AND METHODS}

Based on the literature reviewed, this study has chosen to use Francq et al.'s (2009) framework that has tested the VTE by using misspecified initial parameters so as to extend the application towards GJR-GARCH. Besides the misspecification of the initial parameters, it is also important to study the effects of the model and error distribution assumption misspecification.

This section explains both $\operatorname{GARCH}(1,1)$ and GJR$\operatorname{GARCH}(1,1)$ models, which are the main models used in this study. QMLE and VTE estimators with different types of error distribution that have been used for modelling this study are also being stated. Subsequently, the results of simulations are presented at the end of this section.

In this study, the GARCH model by Bollerslev (1986) has been used to examine the behaviour of volatility in selected financial data. The advantage of GARCH if compared to its predecessors is that the model showed the same performance as the higher order GARCH (Francq \& Zakoïan 2010). Hence, this model has received its popularity as it has always become a benchmark for the construction of new models. Meanwhile, in this model, to ensure stationarity and price elimination unit in the financial data, the returns of stock markets are given by,

$$
r_{t}=100 \times \ln \left(\frac{p_{t}}{p_{t-1}}\right)
$$

where $r_{t}$ is the return of stock closing price at time, $t$ and $p_{t}$ are the current closing prices while $P_{t-1}$ is the price on the day before.

The GARCH $(1,1)$ model take forms as:

$$
\begin{aligned}
& \varepsilon_{t}=z_{t} \sqrt{h_{t}} z_{t} \sim N(0,1) \\
& h_{t}=\omega+\alpha_{1} \varepsilon_{t-1}^{2}+\beta_{1} h_{t-1}
\end{aligned}
$$

with $\omega \geq 0, \alpha \geq 0$ and $\beta \geq 0 . \quad \alpha+\beta<1$ to ensure the stationarity of the GARCH model. On the other hand, as mentioned by the literature, an alternate model that includes the impact of news on volatility has been considered. This model is GJR-GARCH by Glosten et al. (1993).

Glosten et al.'s (1993) version of GARCH has included the effects of both positive and negative news on return volatility. The GJR-GARCH $(1,1)$ equation is written as follows:

$$
h_{t}=\omega+\alpha_{+}\left(\varepsilon_{t-1}^{+}\right)^{2}+\alpha_{-}\left(\varepsilon_{t-1}^{-}\right)^{2}+\beta_{1} h_{t-1}
$$

where $\omega \geq 0, \alpha_{+} \geq 0, \alpha_{-} \geq 0$ and $\beta \geq 0, \alpha_{+}+\frac{\alpha_{-}}{2}+\beta<1$ to ensure the stationarity of GJR-GARCH. Later, the model is infused with $\operatorname{ARMA}(1,0)$ to construct $\operatorname{ARMA}(1,0)$ $\operatorname{GARCH}(1,1)$ and has been applied to real data sets. $\operatorname{ARMA}(1,0)$ takes form as:

$$
r_{t}=\mu+\theta_{1} r_{t-1}
$$

where $r_{t}$ is the same as in (1).

The three common error distribution assumptions that are used in this study are normal distribution, Student's t-distribution and lastly, Generalised Error Distribution (GED). Student's t-distribution was first used by Bollerslev (1987) to capture the heavy tailed error distributions while the GED was used by Nelson (1991) in the ARCH model application.

Normal distribution can be defined by mean and variance. Hence, the random variable $x$ is assumed to be normally distributed with mean $\mu$ and variance $\sigma^{2}$, which in the case of the GARCH model may be time varying because data series are considered to be conditional distributions and thus, the density is given by:

$$
f(x)=\frac{e \frac{-0.5(x-\mu)^{2}}{\sigma^{2}}}{\sigma \sqrt{2 \pi}}
$$


Meanwhile, the residual $\varepsilon$, which is standardised by $\sigma$, gives the standard normal density as specified by,

$$
f\left(\frac{x-\mu}{\sigma}\right)=\frac{1}{\sigma} f(z)=\frac{1}{\sigma}\left(\frac{e^{-0.5 z^{2}}}{\sqrt{2 \pi}}\right)
$$

Next, the conditional likelihood of the GARCH process at each point in time $(L L)$ and the conditional standard deviation $\sigma_{t}$ from the GARCH motion dynamics act as a scaling factor on the density, therefore,

$$
L L_{t}\left(z_{t} ; \sigma_{t}\right)=\frac{1}{\sigma_{t}} f\left(z_{t}\right)
$$

(Note that normal distribution has zero skewedness and zero excess kurtosis)

Furthermore, the difference between the Student's t and normal distributions is the shape parameter of the $v$ as follows:

$$
f(x)=\frac{\Gamma\left(\frac{v+1}{2}\right)}{\sqrt{\beta v \pi} \Gamma\left(\frac{v}{2}\right)}\left(1+\frac{(x-\alpha)^{2}}{\beta v}\right)^{-\left(\frac{v+1}{2}\right)}
$$

where $\alpha, \beta$ and $v$ are the location, scale and shape of the corresponding parameters, while $\Gamma$ is the Gamma function. This shows a unimodal and symmetric distribution where the location parameter $\alpha$ is the mean (and mode) of the distribution, whereas the variance is:

$$
\operatorname{Var}(x)=\frac{\beta v}{(v-2)}
$$

Hence, for standardisation, it is required that

$$
\operatorname{Var}(x)=\frac{\beta v}{(v-2)}=1 \text { thus } \beta=\frac{v-2}{v}
$$

Furthermore, $\left(\frac{v-2}{v}\right)$ is replaced by Equation (9) and forms in the standardised Student's t-distribution

$$
f\left(\frac{x-\varpi}{\sigma}\right)=\frac{1}{\sigma} f(z)=\frac{1}{\sigma} \frac{\Gamma\left(\frac{v+1}{2}\right)}{\sqrt{(v-2) \pi} \Gamma\left(\frac{v}{2}\right)}\left(1+\frac{z^{2}}{(v-2)}\right)^{-\left(\frac{v+1}{2}\right)}
$$

Thus, student distribution has zero skewedness and the excess kurtosis equals to $6 /(v-4)$ for $v>4$.

The Generalised Error Distribution (GED) is a distribution in the exponential family with the conditional density that consists of three parameters, as given by:

$$
f(x)=\frac{\kappa e^{-0.5\left|\frac{z-\alpha}{\beta}\right|_{\kappa}}}{2^{1+\kappa^{-1}} \beta \Gamma\left(\kappa^{-1}\right)}
$$

where $\alpha, \beta$ and $\kappa$ are the location, scale and shape parameters; as the distribution is symmetric and unimodal, hence, the location parameter is also the mode, median and mean of the distribution. The odd moments beyond the mean are zero due to the symmetry characteristic. Meanwhile, variance and kurtosis have been given by:

$$
\begin{aligned}
& \operatorname{Var}(x)=\beta^{2} 2^{2 / k} \frac{\Gamma\left(3 \kappa^{-1}\right)}{\Gamma\left(\kappa^{-1}\right)} \\
& K u(x)=\frac{\Gamma\left(5 \kappa^{-1}\right) \Gamma\left(\kappa^{-1}\right)}{\Gamma\left(3 \kappa^{-1}\right) \Gamma\left(3 \kappa^{-1}\right)}
\end{aligned}
$$

Therefore, as $\kappa$ decreases, the density gets flatter and flatter, while in the limit of $\kappa \rightarrow \infty$, the distribution inclines towards the uniform. Thus, it becomes normal when $\kappa=2$ and Laplace when $\kappa=1$. The standardisation of GED given as:

$$
\begin{aligned}
& \operatorname{Var}(x)=\beta^{2} 2^{2 / k} \frac{\Gamma\left(3 \kappa^{-1}\right)}{\Gamma\left(\kappa^{-1}\right)}=1 \\
& \text { thus } \beta=\sqrt{2^{-2 / \kappa} \frac{\Gamma\left(\kappa^{-1}\right)}{\Gamma\left(3 \kappa^{-1}\right)}}
\end{aligned}
$$

and s (16) is substituted by (12)

yield;

$$
f\left(\frac{x-\mu}{\sigma}\right)=\frac{1}{\sigma} f(z)=\frac{1}{\sigma} \frac{\kappa e^{-\left.0.5 \sqrt{2^{-2 / \kappa} \frac{\Gamma\left(\kappa^{-1}\right)}{\Gamma\left(3 \kappa^{-1}\right)} \mid}\right|_{\kappa}}}{\sqrt{2^{-2 / \kappa} \frac{\Gamma\left(\kappa^{-1}\right)}{\Gamma\left(3 \kappa^{-1}\right)} 2^{1+\kappa^{-1}} \Gamma\left(\kappa^{-1}\right)}}
$$

The asymptotic normality and the consistency of QMLE of the GARCH model have been established by many researches such as Bollerslev and Wooldridge (1992), Lee and Hansen (1994), Ling and McAleer (2002) and Newey and Steigerwald (1997). In the meantime, Verhoeven and McAleer (2004) concluded the need for normality, well specifications of the mean and variance, a strict stationarity of $z_{t}$ and also the needs for various additional moment conditions on $\varepsilon_{t}$ to ensure the consistency of QMLE.

Meanwhile, Francq et al. $(2016,2009)$ and Vaynman and Beare (2013) established the asymptotic properties of VTE. The studies discovered that VTE consists of two steps. First, the unconditional variance of the observed data, which has been estimated by a moment estimator. Second, the remaining parameters, which are estimated by QMLE. The steps are explained as follows:

For $\operatorname{GARCH}(1,1)$ as $(3), \omega$ is replaced by $\bar{\sigma}^{2}(1-\hat{P})$ where $\hat{P}$ is the persistence defined by $\hat{P}=\alpha_{1}+\beta_{1}$ is the unconditional variance of the model $\hat{\sigma}^{2}$ that is related to its persistence, $\hat{\sigma}^{2}=\frac{\hat{\omega}}{1-P}$. For $\operatorname{GJR}-\operatorname{GARCH}(1,1)$, the persistence will be replaced by $\hat{P}=\alpha_{1}+\beta_{1}+\frac{\gamma_{1}}{2}$ and the process remains the same. This shows that VTE is a two-step estimation, because, firstly, the unconditional variances of the underlying data have been estimated using its moment estimator and secondly, the leftover parameters have been estimated by QMLE. 
For the purpose of simulation study, the data is simulated under the GJR-GARCH $(1,1)$ process with the initial parameters of $\omega=0.1, \alpha=0.05, \beta=0.85$ and $\gamma=0.1$. The sample sizes have also been varied to differentiate between small and large sample sizes, hence, two sample sizes of $n=500$ and $n=2500$ have been selected, respectively. In addition, each datasets is generated under iteration process of 1000 times. The data is then simulated under normal distribution as the benchmark because QMLE seems to be desirable if the data is under normal distribution. With regards to this, three misspecification conditions have been imposed, namely parameter estimation under the model misspecification, error distribution misspecification and initial parameter misspecification. The simulation studies will examine the performance of the estimator, when the GJR-GARCH model is being exposed to the presence of three types of misspecification; model error distribution and initial parameter misspecification. For this study, the model with less Akaikes Information Criteria (AIC), Bayesian Information Criteria (BIC) and log likelihood is preferred.
To compare the performances of QMLE and VTE under the misspecified model, the simulated data is modelled using the specifications of $\operatorname{GARCH}(1,1)$. The results, as shown in Table 1, indicate that the parameter estimation with $\operatorname{GARCH}(1,1)$ is better than GJR-GARCH$(1,1)$ under all the specifications. It is also shown that the parameters produced by GARCH $(1,1)$ are more likely to be significant. Besides that, as anticipated, the accuracy increases as the sample size increases. Therefore, even though the data is simulated under $\operatorname{GJR}-\operatorname{GARCH}(1,1)$, the $\operatorname{GARCH}(1,1)$ model still gives good parameter estimations. This may be due to the smaller numbers of parameters that need to be estimated as compared to GJR-GARCH $(1,1)$. Besides that, it is also important to note here that VTE seems to be performing well when compared to QMLE. This is because it has given the lowest AIC, BIC and log likelihood values for all the specifications. On the other hand, VTE seems to increase the standard errors for all parameters as shown in Table 1. Furthermore, with AIC and BIC as the basis for model selection, $\operatorname{GARCH}(1,1)$ with the GED innovation assumption has been selected as the best model for both

TABLE 1. GARCH(1,1) and GJR-GARCH(1,1) models parameters estimation

\begin{tabular}{|c|c|c|c|c|c|c|c|c|c|c|c|c|}
\hline & \multicolumn{2}{|c|}{$\operatorname{GARCH}(1,1)$} & \multicolumn{2}{|c|}{ GJR-GARCH $(1,1)$} & \multicolumn{2}{|c|}{$\operatorname{GARCH}(1,1)$} & \multicolumn{2}{|c|}{ GJR-GARCH $(1,1)$} & \multicolumn{2}{|c|}{$\operatorname{GARCH}(1,1)$} & \multicolumn{2}{|c|}{ GJR-GARCH $(1,1)$} \\
\hline Innovation & \multirow{2}{*}{\multicolumn{4}{|c|}{$\begin{array}{l}\text { Normal } \\
(n=500)\end{array}$}} & \multirow{2}{*}{\multicolumn{4}{|c|}{$\begin{array}{l}\text { Student- } t \\
(n=500)\end{array}$}} & \multirow{2}{*}{\multicolumn{4}{|c|}{$\begin{array}{c}\text { GED } \\
(n=500)\end{array}$}} \\
\hline Assumption & & & & & & & & & & & & \\
\hline Estimator & QMLE & VTE & QMLE & VTE & QMLE & VTE & QMLE & VTE & QMLE & VTE & QMLE & VTE \\
\hline \multirow[t]{2}{*}{$\omega$} & $0.0929 *$ & 0.0932 & $0.1055^{*}$ & 0.1055 & $0.0763^{*}$ & 0.0765 & $0.0911^{*}$ & 0.0911 & $0.0796^{*}$ & 0.0798 & $0.0941^{*}$ & 0.0941 \\
\hline & $(0.0711)$ & & $(0.0705)$ & & $(0.0610)$ & & $(0.0671)$ & & $(0.0648)$ & & $(0.0692)$ & \\
\hline \multirow[t]{2}{*}{$\alpha$} & 0.0856 & $0.0851^{*}$ & $0.0504^{*}$ & 0.0505 & 0.0756 & 0.0751 & $0.0459 *$ & $0.0460 *$ & 0.0785 & 0.0781 & $0.0464^{*}$ & $0.0464 *$ \\
\hline & $(0.0339)$ & $(0.0489)$ & $(0.0339)$ & $(0.0307)$ & $(0.0318)$ & $(0.0328)$ & $(0.0328)$ & $(0.0323)$ & $(0.0332)$ & $(0.0284)$ & $(0.0337)$ & $(0.0324)$ \\
\hline \multirow[t]{2}{*}{$\beta$} & 0.8620 & 0.8619 & 0.8587 & 0.8587 & 0.8813 & 0.8812 & 0.8740 & 0.8740 & 0.8765 & 0.8764 & 0.8704 & 0.8704 \\
\hline & $(0.0660)$ & $(0.1023)$ & $(0.0628)$ & $(0.0544)$ & $(0.0582)$ & $(0.0634)$ & $(0.0601)$ & $(0.0613)$ & $(0.0616)$ & $(0.0559)$ & $(0.0621)$ & $(0.0591)$ \\
\hline \multirow[t]{2}{*}{ AIC } & 3.3588 & 3.3548 & $0.0613^{*}$ & 0.0614 & 3.3568 & 3.3528 & $0.0560^{*}$ & $0.0560 *$ & 3.3551 & 3.3511 & $0.0590^{*}$ & $0.0591 *$ \\
\hline & & & $(0.0474)$ & $(0.0471)$ & & & $(0.0481)$ & $(0.0480)$ & & & $(0.0493)$ & $(0.0483)$ \\
\hline BIC & 3.3926 & 3.3801 & 3.3590 & 3.3550 & 3.3989 & 3.3865 & 3.3576 & 3.3536 & 3.3972 & 3.3848 & 3.3557 & 3.3517 \\
\hline Likelihood & -835.7085 & -835.71 & 3.401 & 3.388 & -834.196 & -834.197 & 3.408 & 3.3958 & -833.764 & -833.764 & 3.406 & 3.393 \\
\hline Times & 0.4936 & 0.0490 & -834.75 & -834.75 & 0.3182 & 0.1030 & -833.40 & -833.40 & 0.1761 & 0.0890 & -832.92 & -832.92 \\
\hline Innovation & \multirow{2}{*}{\multicolumn{4}{|c|}{$\begin{array}{c}\text { Normal } \\
(n=2500)\end{array}$}} & \multirow{2}{*}{\multicolumn{4}{|c|}{$\begin{array}{l}\text { Student- } t \\
(n=2500)\end{array}$}} & \multirow{2}{*}{\multicolumn{4}{|c|}{$\begin{array}{c}\text { GED } \\
(n=2500)\end{array}$}} \\
\hline Assumption & & & & & & & & & & & & \\
\hline Estimator & QMLE & VTE & QMLE & VTE & QMLE & VTE & QMLE & VTE & QMLE & VTE & QMLE & VTE \\
\hline \multirow[t]{2}{*}{$\omega$} & 0.0861 & 0.0861 & 0.0824 & 0.0823 & 0.0865 & 0.0866 & 0.0827 & 0.0828 & 0.0854 & 0.0855 & 0.0819 & 0.0818 \\
\hline & $(0.0212)$ & & 0.0203 & & $(0.0215)$ & & 0.0207 & & $(0.0199)$ & & 0.0192 & \\
\hline \multirow[t]{2}{*}{$\alpha$} & 0.1039 & 0.1038 & 0.0771 & 0.0774 & 0.1041 & 0.1034 & 0.0772 & 0.0771 & 0.1044 & 0.1041 & 0.0777 & 0.0778 \\
\hline & $(0.0145)$ & $(0.0158)$ & 0.0187 & 0.0181 & $(0.0148)$ & $(0.0133)$ & 0.0190 & 0.0192 & $(0.0138)$ & $(0.0128)$ & 0.0177 & 0.0170 \\
\hline \multirow[t]{2}{*}{$\beta$} & 0.8516 & 0.8516 & 0.8593 & 0.8593 & 0.8516 & 0.8517 & 0.8594 & 0.8594 & 0.8515 & 0.8515 & 0.8592 & 0.8592 \\
\hline & $(0.0207)$ & $(0.0255)$ & 0.0205 & 0.0188 & $(0.0210)$ & $(0.0209)$ & 0.0208 & 0.0207 & $(0.0195)$ & $(0.0199)$ & 0.0194 & 0.0277 \\
\hline \multirow[t]{2}{*}{ AIC } & 3.4074 & 3.4066 & $0.0410^{*}$ & $0.0411^{*}$ & 3.4094 & 3.4086 & $0.0412 *$ & $0.0411^{*}$ & 3.4062 & 3.4054 & 0.0408 & $0.0409 *$ \\
\hline & & & 0.0220 & 0.0223 & & & 0.0224 & 0.0226 & & & 0.0208 & 0.0229 \\
\hline BIC & 3.4167 & 3.4136 & 3.4069 & 3.4061 & 3.4210 & 3.4179 & 3.4089 & 3.4081 & 3.4178 & 3.4147 & 3.4055 & 3.4047 \\
\hline Likelihood & -4255.2 & -4255.2 & 3.4185 & 3.4154 & -4256.6 & -4256.7 & 3.4228 & 3.4197 & -4252.7 & -4252.7 & 3.4195 & 3.4163 \\
\hline Times & 0.1941 & 0.2362 & -4253.56 & -4253.58 & 0.6054 & 0.4813 & -4255.08 & -4255.08 & 0.6114 & 0.30721 & -4250.87 & -4250.87 \\
\hline
\end{tabular}

$(*)$ indicate the parameters have p-value $>0.05$. The brackets show the standard errors of each parameter 
small and big data samples. In contrast, by using the $\log$ likelihood indicator, $\operatorname{GARCH}(1,1)$ with Student's t innovation assumption is more preferable for both small and sample data sizes. Thus, normal innovation assumption is not desirable under all of the specifications. Besides that, this study also noticed that the processing times for VTE are less than QMLE under all of the specifications.

Using the framework adapted from Francq et al. (2009), the specification to represent the initial misspecified parameters has been extended to the applications of GJR$\operatorname{GARCH}(1,1)$. Hence, the initial parameters have been setup as $\omega=1, \alpha=0, \beta=0$ and $\gamma=0$. The results in Table 2 shows that the models' performance has reduced from what is indicated in Table 1. This shows that there are many insignificant parameters in this model and this may be due to the simulated data that has been generated under the normal distribution. Under the misspecified initial parameters, VTE did not only outperform QMLE for AIC, BIC and log likelihood, but it showed that the standard errors for each parameter are also less than QMLE. Hence, the results are similar to the ones in Table 1, where AIC and BIC favoured the model under the GED innovation assumption, while log likelihood preferred the Student's t for both small and big sample sizes. As the simulated data has been set to be normally distributed, the estimators' performances under the innovation misspecification can be examined. Here, the models have not been improved even under the well specified innovation assumption.

In terms of the application of real data sets, the daily closing stock market indices from three major ASEAN countries have been collected. For this study, the FTSE Bursa Malaysia Kuala Lumpur Composite Index (FBMKLCI), the Singapore Straits Times Index (STI) and the Indonesia Jakarta Composite Index (JCI) have been selected. The data has been obtained from the Thomson Reuters Datastream and consists of historical data from a five-year period starting from $16^{\text {th }}$ August 2010 until 14 $4^{\text {th }}$ August 2015.
Table 2 shows the descriptive statistics for all three times series. Of all the stock markets, JCI experienced higher average returns $(0.0336 \%)$ when compared to STI and FBMKLCI, but it also produced the highest standard deviation. Furthermore, all of the series were found to be leptokurtic and skewed to the left. Based on the JarqueBera test, all series rejected the null hypotheses of normal distribution. In addition, the null hypotheses for the unit root tests are rejected as shown by the ADF and PP test. As for the KPSS test, the null hypothesis of stationarity is accepted, while the ARCH Lagrange Multiplier test for conditional heteroscedasticity has given a significant arch effect in the time series. Hence, it is suitable to implement the GARCH model into these three time series.

Therefore, to infuse the GARCH model with the ARMA model, a simple diagnostic using AIC has been used to select the best ARMA order. Here, ARMA $(1,0)$ has given the lowest AIC, thus, it has been selected to accommodate the GARCH model. As the study focuses on GJR-GARCH, the full model is ARMA(1,0)-GJR-GARCH( $(1,1)$.

\section{RESULTS AND DISCUSSION}

To investigate how QMLE and VTE performed under real data sets, the indicators on which models to select still used the same measurements from the simulation study. Hence, the lowest AIC, BIC and log likelihood have been preferred. Meanwhile, in the real environments, the true characteristic of the series has been commonly unknown; this is why practitioners always considered the alternative model and estimators, to ensure which are the best models to project future volatility. Thus, three data sets, namely FBMKLCI, STI and JCI, are modelled under ARMA(1-0)-GJR$\operatorname{GARCH}(1,1)$. Furthermore, two innovation assumptions, the Student's t and GED distributions, have been used as the previous descriptive statistics have stated that the series are not normally distributed (Table 3).

TABLE 2. Descriptive statistics for all times series

\begin{tabular}{lllc}
\hline & FBMKLCI & STI & JCI \\
Panel A: Basic descriptive statistics & & & \\
\hline Mean & 0.0103 & 0.0045 & 0.0336 \\
Median & 0.0149 & 0.0046 & 0.0996 \\
Std. dev. & 0.5602 & 0.7567 & 1.1312 \\
Skewness & -0.3454 & -0.5195 & -0.8694 \\
Kurtosis & 5.9590 & 6.1775 & 9.7392 \\
JarqueBera & $481.67^{* *}$ & $607.27^{* *}$ & $2363.5^{* *}$ \\
Panel B: unit root and stationarity test & & & \\
ADF & $-10.462^{* *}$ & $-11.003^{* *}$ & $-9.868^{* *}$ \\
PP & $-1071.4 * *$ & $-1255^{* *}$ & $-965.78^{* *}$ \\
KPSS & 0.3814 & 0.0503 & 0.14721 \\
Panel C: heterocedasticity test & & \\
ARCH LM Test & $119.82^{* *}$ & $181.1 * *$ & $169.32^{* *}$ \\
\hline (**) Denotes the rejection of the null hypothesis of normality, unit root, stationarity and ARCH effect at the $1 \%$ significance level
\end{tabular}


TABLE 3. AIC of ARMA order for all series

\begin{tabular}{lccc}
\hline & FBMKLCI & STI & JCI \\
\hline ARMA(0,0) & 2105.16 & 2976.6 & 3615 \\
ARMA(1,0) & 2089.87 & 2975.45 & 3613.65 \\
ARMA(0,1) & 2091.78 & 2975.55 & 3613.67 \\
ARMA(1,1) & 2090.7 & 2977.27 & 3615.65 \\
\hline
\end{tabular}

As shown in Table 4, only the model under the GED innovation assumptions has given all parameters that are significant. Thus, based on the log likelihood value, the models with GED under the VTE estimators have been the best, except for the Student's t under the same estimator, which has shown to be the best model, if the selection is based on AIC and BIC. Therefore, the model is well fitted since the ARCH Lagrange Multiplier at lag 5 (LM (5)) has shown insignificant ARCH effect after the data was modelled using ARMA $(1,0)$-GJR-GARCH $(1,1)$. Furthermore, the sign bias ( $\mathrm{SB}$ ), the negative sign bias (NSB) and the positive sign bias (PSB) tests have also been given the insignificant value and this shows that the models have captured the effects' signs effectively as the sign bias test is the test on the magnitude of the square on the current shock $\varepsilon_{t}$. Hence, the conditional variance $h_{t}$ depends on the sign of the lagged shock $\varepsilon_{t-1}$. Furthermore, STI, as shown in the results in Table 5, is the best model and is also in parallel with the FBMKLCI results, where the model with Student's t innovation under the VTE estimator is preferred using the log likelihood value, while the GED with VTE estimator is preferable when AIC and BIC are being used. This is because the use of VTE on STI series seems to reduce the parameters for standard error. Meanwhile, the JCI results in Table 6 seem to produce slightly different results from STI and FBMKLCI; however, it is still the best model under the VTE estimation. Moreover, the parameter standard error has also been reduced when the model is estimated using VTE.

\section{CONCLUSION}

In conclusion, there are three misspecification conditions of the GARCH model that have been considered to evaluate both QMLE and VTE. From the results of the simulation, VTE seems to perform better as compared to QMLE, based on AIC, BIC and log likelihood values. VTE has reduced the number of parameters that need to be estimated. On the other hand, GED and Student's $\mathrm{t}$ innovation assumptions have performed better when compared to normal distribution. This is because normally, distributed data can cause the parameters in GJR-GARCH to be insignificant. However, as commonly understood, financial data is, literally, not normally distributed; hence, a well specified error distribution assumption, which in this study is normally distributed, has not increased the model's performance. Furthermore, as shown by the application

TABLE 4. Estimation results of $\operatorname{ARMA}(1,0)-G J R-G A R C H(1,1)$ for expectation of FBMKLCI returns

\begin{tabular}{|c|c|c|c|c|}
\hline \multirow{2}{*}{$\begin{array}{l}\text { Innovation } \\
\text { Assumption } \\
\text { Estimator }\end{array}$} & \multicolumn{2}{|c|}{ Student-t } & \multicolumn{2}{|c|}{ GED } \\
\hline & QMLE & VTE & QMLE & VTE \\
\hline Mean & $\begin{array}{c}0.0284 \\
(0.0136)\end{array}$ & $\begin{array}{c}0.0278 \\
(0.0138)\end{array}$ & $\begin{array}{c}0.0225 \\
(0.0108)\end{array}$ & $\begin{array}{c}0.0213 \\
(0.0077)\end{array}$ \\
\hline MA (1) & $\begin{array}{c}0.0746 \\
(0.0282)\end{array}$ & $\begin{array}{c}0.0745 \\
(0.0282)\end{array}$ & $\begin{array}{c}0.0547 \\
(0.0214)\end{array}$ & $\begin{array}{c}0.0533 \\
(0.0172)\end{array}$ \\
\hline Omega & $\begin{array}{c}0.0089 \\
(0.0038)\end{array}$ & 0.0091 & $\begin{array}{c}0.0118 \\
(0.0048)\end{array}$ & 0.0119 \\
\hline Alpha (1) & $\begin{array}{l}0.0205^{*} \\
(0.0169)\end{array}$ & $\begin{array}{l}0.0225^{*} \\
(0.0201)\end{array}$ & $\begin{array}{c}0.0227 \\
(0.0190)\end{array}$ & $\begin{array}{c}0.0267 \\
(0.0228)\end{array}$ \\
\hline Beta (1) & $\begin{array}{c}0.9053 \\
(0.0261)\end{array}$ & $\begin{array}{c}0.9042 \\
(0.0379)\end{array}$ & $\begin{array}{c}0.8887 \\
(0.0316)\end{array}$ & $\begin{array}{c}0.8860 \\
(0.0445)\end{array}$ \\
\hline Gamma (1) & $\begin{array}{c}0.0832 \\
(0.0277)\end{array}$ & $\begin{array}{c}0.0856 \\
(0.0314)\end{array}$ & $\begin{array}{c}0.0899 \\
(0.0315)\end{array}$ & $\begin{array}{c}0.0945 \\
(0.0361)\end{array}$ \\
\hline LM (5) & 2.378 & 2.426 & 2.744 & 2.874 \\
\hline SB & 1.9621 & 1.9567 & 1.9151 & 1.8591 \\
\hline NSB & 1.2213 & 1.1803 & 1.1811 & 1.0875 \\
\hline PSB & 0.4259 & 0.3834 & 0.4698 & 0.3379 \\
\hline Times & 1.1118 & 0.4002 & 1.0667 & 0.6274 \\
\hline Log-likelihood & -873.3173 & -873.373 & -874.7537 & -874.9312 \\
\hline AIC & 1.4408 & 1.4392 & 1.4431 & 1.4418 \\
\hline BIC & 1.4700 & 1.4643 & 1.4724 & 1.4669 \\
\hline
\end{tabular}

(*) indicate the parameters have $p$-value $>0.05$. The bracket show the standard error of each parameter 
TABLE 5. The Estimation results of $\operatorname{ARMA}(1,0)$-GJR-GARCH $(1,1)$ for expectation of STI returns

\begin{tabular}{|c|c|c|c|c|}
\hline \multirow{2}{*}{$\begin{array}{l}\text { Innovation } \\
\text { Assumption } \\
\text { Estimator }\end{array}$} & \multicolumn{2}{|c|}{ Student-t } & \multicolumn{2}{|c|}{ GED } \\
\hline & QMLE & VTE & QMLE & VTE \\
\hline Mean & $\begin{array}{l}0.0210 * \\
(0.0166)\end{array}$ & $\begin{array}{l}0.0150 * \\
(0.0160)\end{array}$ & $\begin{array}{c}0.0178 \\
(0.0156)\end{array}$ & $\begin{array}{c}0.0130 * \\
(0.0111)^{*}\end{array}$ \\
\hline MA (1) & $\begin{array}{l}0.0024 * \\
(0.0278)\end{array}$ & $\begin{array}{l}0.0024 * \\
(0.0270)\end{array}$ & $\begin{array}{c}-0.0008 \\
(0.0268)\end{array}$ & $\begin{array}{l}-0.0012 \\
(0.0194)\end{array}$ \\
\hline Omega & $\begin{array}{c}0.0046 \\
(0.0016)\end{array}$ & 0.0045 & $\begin{array}{c}0.0050 \\
(0.0019)\end{array}$ & 0.0048 \\
\hline Alpha (1) & $\begin{array}{l}0.0002 * \\
(0.0111)\end{array}$ & $\begin{array}{l}0.0072 * \\
(0.0043)\end{array}$ & $\begin{array}{c}0.0050 \\
(0.0132)\end{array}$ & $\begin{array}{l}0.0116 * \\
(0.0104)\end{array}$ \\
\hline Beta (1) & $\begin{array}{c}0.9511 \\
(0.0088)\end{array}$ & $\begin{array}{c}0.9461 \\
(0.0001)\end{array}$ & $\begin{array}{c}0.9459 \\
(0.0121)\end{array}$ & $\begin{array}{c}0.9414 \\
(0.0000)\end{array}$ \\
\hline Gamma (1) & $\begin{array}{c}0.0729 \\
(0.0156)\end{array}$ & $\begin{array}{c}0.0772 \\
(0.0063)\end{array}$ & $\begin{array}{c}0.0730 \\
(0.0173)\end{array}$ & $\begin{array}{c}0.0766 \\
(0.0185)\end{array}$ \\
\hline LM (5) & 0.2075 & 0.0782 & 0.0782 & 0.0848 \\
\hline $\mathrm{SB}$ & 1.9069 & $2.0144 * *$ & 1.7819 & 1.8324 \\
\hline NSB & 0.5626 & 0.8438 & 0.5954 & 0.8337 \\
\hline PSB & 0.8177 & 0.9335 & 0.9530 & 1.0933 \\
\hline Times & 0.8155 & 0.4513 & 0.9256 & 0.6444 \\
\hline Log-likelihood & -1275.378 & -1276.114 & -1272.045 & -1272.608 \\
\hline AIC & 2.0132 & 2.0127 & 2.0079 & 2.0072 \\
\hline $\mathrm{BIC}$ & 2.0414 & 2.0370 & 2.0362 & 2.0315 \\
\hline
\end{tabular}

$(*)$ indicate the parameters have $p$-value $>0.05$. The bracket show the standard error of each parameter

TABLE 6. The Estimation results of $\operatorname{ARMA}(1,0)-\operatorname{GJR}-\operatorname{GARCH}(1,1)$ for expectation of JCI returns

\begin{tabular}{lcccc}
\hline Innovation & \multicolumn{2}{c}{ Student-t } & \multicolumn{2}{c}{ GED } \\
Assumption & QMLE & VTE & QMLE & VTE \\
\hline Estimator & 0.0831 & 0.0804 & 0.0969 & 0.0928 \\
Mean & $(0.0242)$ & $(0.0244)$ & $(0.0269)$ & $(0.0199)$ \\
& $-0.0214 *$ & $-0.0213 *$ & $-0.0268 *$ & -0.0250 \\
MA (1) & $(0.0316)$ & $(0.0337)$ & $(0.0336)$ & $(0.0121)$ \\
& 0.0317 & 0.0313 & 0.0322 & 0.0303 \\
Omega & $(0.0105)$ & & $(0.0110)$ & \\
& $0.0225 *$ & $0.0336 *$ & $0.0234 *$ & 0.0435 \\
Alpha (1) & $(0.0196)$ & $(0.0191)$ & $(0.0206)$ & $(0.0138)$ \\
& 0.8976 & 0.8937 & 0.8965 & 0.8894 \\
Beta (1) & $(0.0218)$ & $(0.0108)$ & $(0.0228)$ & $(0.0035)$ \\
& 0.0921 & 0.0961 & 0.0882 & 0.0866 \\
Gamma (1) & $(0.0293)$ & $(0.0326)$ & $(0.0298)$ & $(0.0225)$ \\
& 1.9794 & 2.0901 & 1.9312 & 2.1247 \\
LM (5) & 1.6702 & 1.5019 & 1.5094 & 1.5287 \\
SB & 0.1338 & 0.2136 & 0.0207 & 0.2268 \\
NSB & 0.5967 & 0.7874 & 0.6561 & 0.8165 \\
PSB & 0.6454 & 0.3522 & 0.8516 & 0.5853 \\
BIC & -1564.181 & -1564.801 & -1570.625 & -1571.708 \\
\hline & 2.7540 & 2.7534 & 2.7653 & 2.7655 \\
BIC & 2.7850 & 2.7799 & 2.7963 & 2.7920 \\
\hline
\end{tabular}

$(*)$ indicate the parameters have $p$-value $>0.05$. The bracket shows the standard error of each parameter 
of these models to real data sets by modelling the three major indices, FBMKLCI, STI and JCI, it can be concluded that VTE has performed very well. Therefore, based on the findings of this study, it can be concluded that it is best to use alternative estimators rather than QMLE in modelling GARCH and specifically, GJR-GARCH, under assumption of misspecified model.

\section{ACKNOWLEDGEMENTS}

The authors would like to thank the Ministry of Higher Education (MOHE), Malaysia and Research Management Institute (RMI) of Universiti Teknologi MARA, Malaysia for supporting this project under the Fundamental Research Grant Scheme (600-RMI/FRGS 5/3 (0086/2016)).

\section{REFERENCES}

Abdul Rahim, M.A., Zahari, S.M. \& Shariff, S.S.R. 2017. Performance of variance targeting estimator (VTE) under misspecified error distribution assumption. Pertanika Journal of Science and Technology 25(2): 607-618.

Almeida, D.D. \& Hotta, L.K. 2014. The leverage effect and the asymmetry of the error distribution in GARCH-based models: The case of Brazilian market related series. Pesquisa Operacional 34(2): 237-250.

Black, F. 1976. Studies in stock price volatility changes. Proceedings of the 1976 Business.

Bollerslev, T. 1987. A conditionally heteroskedastic time series model for speculative prices and rates of return. The Review of Economics and Statistics 16(3): 542-547.

Bollerslev, T. 1986. Generalized autoregressive conditional heteroskedasticity. Journal of Econometrics 31(3): 307-327.

Bollerslev, T. \& Wooldridge, J.M. 1992. Quasi-maximum likelihood estimation and inference in dynamic models with time-varying covariances. Econometric Reviews 11(2): 143-172.

Boudt, K., Danielsson, J. \& Laurent, S. 2013. Robust forecasting of dynamic conditional correlation GARCH models. International Journal of Forecasting 29(2): 244-257.

Boudt, K. \& Croux, C. 2010. Robust M-estimation of multivariate GARCH models. Computational Statistics \& Data Analysis 54(11): 2459-2469.

Cappiello, L., Engle, R.F. \& Sheppard, K. 2006. Asymmetric dynamics in the correlations of global equity and bond returns. Journal of Financial Econometrics 4(4): 537-572.

Casarin, R., Chang, C.L., Jiménez-Martín, J.Á., McAleer, M. \& Pérez-Amaral, T. 2013. Risk management of risk under the Basel Accord: A Bayesian approach to forecasting valueat-risk of VIX futures. Mathematics and Computers in Simulation 94: 183-204.

Dutta, A. 2014. Modelling volatility: Symmetric or asymmetric Garch models. Journal of Statistics: Advances in Theory and Applications 12(2): 99-108.

Engle, R.F. 1982. Autoregressive conditional heteroscedasticity with estimates of the variance of United Kingdom inflation. Econometrica: Journal of the Econometric Society 50(4): 987-1007.

Engle, R.F. \& Mezrich, J. 1996. GARCH for groups: A round-up of recent developments in Garch techniques for estimating correlation. Risk 9(8): 36-40.
Engle, R.F. \& Ng, V.K. 1993. Measuring and testing the impact of news on volatility. The Journal of Finance 48(5): 1749-1778.

Foucault, T., Hombert, J. \& Roşu, I. 2016. News trading and speed. The Journal of Finance 71(1): 335-382.

Francq, C. \& Zakoïan, J.M. 2010. GARCH Models: Structure, Statistical Inference and Financial Applications. New York: John Wiley \& Sons.

Francq, C., Horváth, L. \& Zakoïan, J.M. 2016. Variance targeting estimation of multivariate GARCH models. Journal of Financial Econometrics 14(2): 353-382.

Francq, C., Horvath, L. \& Zakoïan, J.M. 2009. Merits and drawbacks of variance targeting in GARCH models. Journal of Financial Econometrics 9(4): 619-656.

Glosten, L.R., Jagannathan, R. \& Runkle, D.E. 1993. On the relation between the expected value and the volatility of the nominal excess return on stocks. The Journal of Finance 48(5): 1779-1801.

Iqbal, F. 2013. Robust estimation of the simplified multivariate GARCH model. Empirical Economics 44(3): 1-20.

Islam, R. \& Sultana, N. 2015. Day of the week effect on stock return and volatility: Evidence from Chittagong stock exchange. European Journal of Business and Management 7(3): 165-172.

Lee, S.W. \& Hansen, B.E. 1994. Asymptotic theory for the GARCH $(1,1)$ quasi-maximum likelihood estimator. Econometric Theory 10(1): 29-52.

Lim, C.M. \& Sek, S.K. 2013. Comparing the performances of GARCH-type models in capturing the stock market volatility in Malaysia. Procedia Economics and Finance 5: 478-487.

Ling, S. \& McAleer, M. 2002. Stationarity and the existence of moments of a family of GARCH processes. Journal of Econometrics 106(1): 109-117.

Maheu, J.M. \& McCurdy, T.H. 2004. News arrival, jump dynamics, and volatility components for individual stock returns. The Journal of Finance 59(2): 755-793.

Mehdian, S. \& Perry, M.J. 2001. The reversal of the Monday effect: New evidence from US equity markets. Journal of Business Finance \& Accounting 28(7-8): 1043-1065.

Mukherjee, K. 2008. M-estimation in GARCH models. Econometric Theory 24(6): 1530-1553.

Muler, N. \& Yohai, V.J. 2008. Robust estimates for GARCH models. Journal of Statistical Planning and Inference 138(10): 2918-2940.

Narayan, P.K. \& Smyth, R. 2005. Cointegration of stock markets between New Zealand, Australia and the G7 economies: Searching for co-movement under structural change. Australian Economic Papers 44(3): 231-247.

Nelson, D.B. 1991. Conditional heteroskedasticity in asset returns: A new approach. Econometrica: Journal of the Econometric Society 59(2): 347-370.

Nelson, D.B. \& Foster, D.P. 1995. Filtering and forecasting with misspecified ARCH models II: making the right forecast with the wrong model. Journal of Econometrics 67(2): 303-335.

Newey, W.K. \& Steigerwald, D.G. 1997. Asymptotic bias for quasi-maximum-likelihood estimators in conditional heteroskedasticity models. Econometrica: Journal of the Econometric Society 65(3): 587-599.

Oh, S.L., Lau, E., Puah, C.H. \& Mansor, S.A. 2010. Volatility comovement of Asean-5 equity markets. Journal of Advanced Studies in Finance 1(1): 23-30.

Pedersen, R.S. \& Rahbek, A. 2014. Multivariate variance targeting in the BEKK-GARCH model. The Econometrics Journal 17(1): 24-55. 
Peng, L. \& Yao, Q. 2003. Least absolute deviations estimation for ARCH and GARCH models. Biometrika 90(4): 967-975.

Shamiri, A. \& Isa, Z. 2009. Modeling and forecasting volatility of the Malaysian stock markets. Journal of Mathematics and Statistics 5(3): 234-240.

Thalassinos, E.I., Ugurlu, E. \& Muratoglu, Y. 2014. Comparison of forecasting volatility in the Czech Republic stock market. Applied Economics and Finance 2(1): 11-18.

Tsukuda, Y., Shimada, J. \& Miyakoshi, T. 2017. Bond market integration in East Asia: Multivariate GARCH with dynamic conditional correlations approach. International Review of Economics \& Finance 51: 193-213.

Vaynman, I. \& Beare, B.K. 2014. Stable limit theory for the variance targeting estimator. In Essays in Honor of Peter CB Phillips, edited by Chang, Y.S., Fomby, T.B. \& Park, J.Y. Bingley: Emerald Group Publishing Limited. pp. 639-672.

Verhoeven, P. \& McAleer, M. 2004. Fat tails and asymmetry in financial volatility models. Mathematics and Computers in Simulation 64(3): 351-361.
Yaya, O.S., Olubusoye, O.E. \& Ojo, O.O. 2014. Estimates and forecasts of GARCH model under misspecified probability distributions: A Monte Carlo simulation approach. Journal of Modern Applied Statistical Methods 13(2): 479-492.

Centre for Statistical and Decision Science Studies Faculty of Computer and Mathematical Sciences Universiti Teknologi MARA 45450 UiTM Shah Alam, Selangor Darul Ehsan Malaysia

*Corresponding author: mariam@tmsk.uitm.edu.my

Received: 21 November 2017

Accepted: 17 May 2018 